\title{
HUBUNGAN HASIL BELAJAR GAMBAR TEKNIK DAN MOTIVASI KERJA SISWA DENGAN HASIL BELAJAR INSTALASI PENERANGAN LISTRIK DALAM PROGRAM KEAHLIAN TEKNIK INSTALASI TENAGA LISTRIK KELAS XI DI SMK NEGERI 55 JAKARTA TAHUN AJARAN 2019/2020
}

${ }^{1}$ Annisa Inggerid Tara Dia, ${ }^{2}$ Faried Wadjdi, ${ }^{3}$ Aris Sunawar

1,2,3 Pendidikan Teknik Elektro, Fakultas Teknik, Universitas Negeri Jakarta

1,2,3 Email: Annisainggerid@gmail.com, faried@unj.ac.id, arissunawar@unj.ac.id

\begin{abstract}
This study aimed to describe the correlation between electrical drawing learning outcomes and student motivation to work with electrical lighting installation learning outcomes of class XI TITL of SMKN 55 Jakarta with a sample of 92 students using the ex-post facto research method. The data analysis were collected by questionnaire and documentation. Based on the result of the analysis of these data, there is a linear and normal distribution. This research using method of hypothesis is Product Moment Correlation. Based on the result, the correlation value are $r_{y x l}=0,400, r_{y x z}=0,334, r_{y x l x 2}=0,513$, $r_{\text {table }}=0,205$ ( $\left.r_{\text {count }}>r_{\text {table }} 5 \%\right)$ means (1) There is a positive correlation of engineering draw learning outcomes with electrical lighting installation learning outcomes. (2) There is positive correlation of student work motivation with electrical lighting installation learning outcomes (3) There is positive correlation of engineering draw learning outcomes and student work motivation with electrical lighting installation learning outcomes. Based on result, the higher electrical drawing learning outcomes and student motivation to work are then electrical lighting installation learning outcomes of class XI TITL of SMKN 55 Jakarta as well.

Keywords: electrical drawing learning outcomes, student work motivation, electrical lighting installation learning outcomes
\end{abstract}

\begin{abstract}
Abstrak
Tujuan penelitian ini untuk mengetahui adanya hubungan hasil belajar gambar teknik dan motivasi kerja siswa dengan hasil belajar instalasi penerangan listrik kelas XI TITL di SMKN 55 Jakarta dengan sampel sebanyak 92 siswa yang menggunakan metode penelitian ex-post facto. Teknik pengumpulan data menggunakan angket dan dokumentasi. Hasil pengujian prasyarat analisis menyatakan bahwa data penelitian bersifat linier dan berdistribusi normal. Pengujian hipotesis penelitian menggunakan uji korelasi product moment. Hasil pengujian hipotesis penelitian ini terlihat dari nilai korelasi $\mathrm{r}_{\mathrm{yx} 1}=0,400, \mathrm{r}_{\mathrm{yx} 2}=0,334, \mathrm{r}_{\mathrm{yx} 1 \times 2}=0,513$ dengan $r_{\text {tabel }}=0,205\left(r_{\text {hitung }}>r_{\text {tabel }} 5 \%\right.$ ) yang artinya (1) Terdapat hubungan yang positif antara hasil belajar gambar teknik dengan hasil belajar instalasi penerangan listrik. (2) Terdapat hubungan yang positif antara motivasi kerja siswa dengan hasil belajar instalasi penerangan listrik. (3) Terdapat hubungan yang positif antara hasil belajar gambar teknik dan motivasi kerja siswa dengan hasil belajar instalasi penerangan listrik kelas XI TITL di SMKN 55 Jakarta. Berdasarkan hasil tersebut, disimpulkan bahwa semakin tinggi hasil belajar gambar teknik dan motivasi kerja siswa maka akan meningkat pula hasil belajar instalasi penerangan listrik siswa kelas XI Program Keahlian Teknik Instalasi Penerangan Listrik di SMK Negeri 55 Jakarta.
\end{abstract}

Kata kunci: Hasil Belajar Gambar Teknik, Motivasi Kerja Siswa, Hasil Belajar Instalasi Penerangan Listrik

\section{PENDAHULUAN}

Sebagai bagian dari sistem pendidikan, Sekolah Menengah Kejuruan (SMK) berperan penting dalam meningkatkan kualitas siswa yang memiliki kecerdasan, pengetahuan, kepribadian, serta keterampilan untuk bekerja mandiri dan berdisiplin tinggi sesuai dengan tuntutan dunia kerja. Berdasarkan peran tersebut, maka siswa SMK kejuruan teknik listrik diharapkan mampu menguasai beberapa mata pelajaran sesuai kompetensinya yaitu gambar teknik dan instalasi penerangan listrik agar dapat nantinya menerapkan ilmu di lapangan kerja. Usaha yang dilakukan untuk meningkatkan kualitas siswa terhadap pengetahuan dan keterampilan ialah melalui peningkatan kualitas pembelajaran. [1] Sesuai dengan pernyataan Achjar Chalil (2008:62) bahwa pembelajaran adalah suatu proses interaksi antara siswa, guru, dan sumber belajar pada suatu lingkungan belajar. Apabila terjadi interaksi yang baik antara ketiga aspek tersebut, maka akan menghasilkan hasil belajar yang optimal.

${ }^{[2]}$ Menurut Fathimah Ahmad (2014:27) hasil belajar siswa adalah penilaian usaha belajar yang telah dicapai siswa untuk menunjukan perubahan tingkah laku sebagai umpan balik dalam ranah pengetahuan, sikap, dan keterampilan yang dinilai dalam periode tertentu. Salah satu mata pelajaran yang mengandung tiga unsur ranah pengetahuan, keterampilan dan sikap tersebut ialah instalasi penerangan listrik. $\quad{ }^{[3]}$ Nana Sudjana (2009:3)mengemukakan bahwa keberhasilan suatu hasil belajar instalasi penerangan listrik dapat dilihat melalui beberapa aspek diantaranya pengetahuan dalam instalasi 
penerangan 1 fasa sesuai dengan persyaratan umum instalasi penerangan listrik (PUIL), penggunaan dan persyaratan komponen instalasi listrik, keterampilan dalam merangkai dan memasang rangkaian instalasi, serta sikap yang aktif, bekerja sama dan disiplin selama kegiatan pembelajaran berlangsung. [4] Muhammad Arif (2013:2) mengatakan bahwa untuk mencapai keberhasilan dalam hasil belajar instalasi penerangan listrik, siswa harus memiliki pemahaman dalam mata pelajaran gambar teknik, hal ini karena gambar teknik merupakan salah satu alat penunjang untuk mempermudah pemahaman dasar-dasar instalasi penerangan listrik. Di dalam pembelajaran instalasi penerangan listrik memerlukan pula motivasi agar dapat menggerakkan seseorang untuk bekerja. ${ }^{[5]} \mathrm{Hal}$ ini disampaikan oleh Prastya Irawan (2009:162) bahwa motivasi merupakan faktor yang paling baik untuk mempengaruhi hasil belajar. [6] Rismawati Sugiyanto (2016:438) dalam penelitiannya yang mengatakan bahwa adanya pengaruh yang positif antara hasil belajar instalasi penerangan listrik dengan motivasi kerja siswa.

Berdasarkan observasi dan wawancara dengan guru teknik instalasi tenaga listrik masih terdapat beberapa kendala pada saat pembelajaran yaitu kurangnya penjelasan peragaan alat yang digunakan dan siswa tidak terlalu paham dalam menterjemahkan gambar diagram tunggal dan pengawatannya sehingga menimbulkan pemahaman siswa yang rendah serta motivasi kerja siswa yang diduga kurang karena tidak dapat menyelesaikan tugas dengan tepat waktu. Kendala-kendala tersebut nantinya akan berpengaruh kepada hasil belajar instalasi penerangan listrik yang tidak optimal.

\section{METODOLOGI PENELITIAN}

Jenis desain penelitian ini termasuk dalam penelitian deskriptif korelatif. ${ }^{[7]}$ Penelitian ini menggunakan pendekatan kuantitatif yaitu dengan pengumpulan data menggunakan instrument penelitian, analisis data bersifat kuantitatif/statistik dengan tujuan untuk menguji hipotesis yang telah ditetapkan (Sugiyono,2011:15). Penelitian ini ditujukan untuk menguji hipotesis yang telah diajukan dengan cara mencari besarnya hubungan variabel bebas terhadap variabel terikat.

Populasi dalam penelitian ini adalah siswa kelas XI program kejuruan Teknik Instalasi Tenaga Listrik di SMK Negeri 55 Jakarta sebanyak 92 siswa. Teknik sampling yang digunakan adalah teknik sampling jenuh atau semua populasi dijadikan sebagai sampel. Teknik pengumpulan data untuk variabel hasil belajar gambar teknik dan hasil belajar instalasi penerangan listrik menggunakan dokumentasi dan variabel motivasi kerja siswa menggunakan kuesioner (angket). Instrumen penelitian diuji validitasnya menggunakan rumus korelasi pearson's Product Moment. Pengujian reliabilitas pada instrumen kuesioner (angket) menggunakan koefisien reliabilitas Alfa Cronbach. Teknik analisis data yang digunakan dalam penelitian ini adalah statistic deskriptif. Pengujian hipotesis dalam penelitian ini menggunakan nilai $\mathrm{a}=0,05$, namun sebelum melakukan uji hipotesis terlebih dahulu dilakukan uji normalitas menggunakan Chi kuadrat dan linieritas. Selanjutnya setelah melakukan uji normalitas dan uji linieritas maka dilakukan uji hipotesis menggunakan analisis korelasi Pearson's Product Moment.

\section{HASIL DAN PEMBAHASAN Hasil Belajar Instalasi Penerangan Listrik}

Berikut adalah distribusi frekuensi nilai hasil belajar instalasi penerangan listrik yang dapat dilihat pada Tabel 1.

Tabel 1. Distribusi Frekuensi Data Hasil Belajar Instalasi Penerangan Listrik

\begin{tabular}{lccc}
\hline \multirow{2}{*}{ No } & Kelas & Tepi Kelas & f \\
& Interval & & \\
\hline 1. & $55-59$ & $54,5-59,5$ & 5 \\
2. & $60-64$ & $59,5-64,5$ & 5 \\
3. & $65-69$ & $64,5-69,5$ & 8 \\
4. & $70-74$ & $69,5-74,5$ & 17 \\
5. & $75-79$ & $74,5-79,5$ & 28 \\
6. & $80-84$ & $79,5-84,5$ & 17 \\
7. & $85-89$ & $84,5-89,5$ & 12 \\
\hline \multicolumn{3}{c}{ Jumlah: } & \multicolumn{2}{c}{92} \\
\hline
\end{tabular}


Berdasarkan tabel distribusi frekuensi 1 dapat dilihat bahwa variabel hasil belajar instalasi penerangan listrik memiliki frekuensi tertinggi yaitu sebesar 75-79 dan memiliki frekuensi relatif sebesar 30\% dari total sampel, sedangkan frekuensi terendah yang terletak pada interval kelas ke 1 (satu) antara 55 - 59.

\section{Motivasi Kerja Siswa}

Berikut adalah distribusi frekuensi nilai motivasi kerja siswa yang dapat dilihat pada Tabel 2.

Tabel 2. Distribusi Frekuensi Data Motivasi Kerja Siswa

\begin{tabular}{lccc}
\hline No & Kelas Interval & Tepi Kelas & $\mathrm{f}$ \\
\hline 1. & $72-79$ & $71,5-79,5$ & 1 \\
2. & $80-87$ & $79,5-87,5$ & 2 \\
3. & $88-95$ & $87,5-95,5$ & 8 \\
4. & $96-103$ & $95,5-103,5$ & 36 \\
5. & $104-111$ & $103,5-111,5$ & 26 \\
6. & $112-119$ & $111,5-119,5$ & 13 \\
7. & $120-127$ & $119,5-127,5$ & 6 \\
\hline & Jumlah & & 92 \\
\hline
\end{tabular}

Berdasarkan tabel distribusi frekuensi 2 bisa diketahui bahwa variabel motivasi kerja siswa dengan internal yang memiliki frekuensi tertinggi yaitu sebesar 96 - 103 dan memiliki frekuensi relatif sebesar 39\% dari total sampel, sedangkan frekuensi terendah yang terletak pada interval kelas ke 1 (satu) antara $72-79$ dengan frekuensi relatif sebesar $1 \%$ dari total sampel.

\section{Hasil Belajar Gambar Teknik}

Berikut adalah distribusi frekuensi hasil belajar gambar teknik yang dapat dilihat pada Tabel 3.

Tabel 3. Distribusi Frekuensi Data Hasil Belajar Gambar Teknik

\begin{tabular}{|c|c|c|c|}
\hline \multicolumn{4}{|c|}{ Kelas } \\
\hline No & Interval & Tepi Kelas & $\mathrm{F}$ \\
\hline 1. & $50-55$ & $49,5-55,5$ & 5 \\
\hline 2. & $56-61$ & $55,5-61,5$ & 6 \\
\hline 3. & $62-67$ & $61,5-67,5$ & 9 \\
\hline 4. & $68-73$ & $67,5-73,5$ & 22 \\
\hline
\end{tabular}

\begin{tabular}{cccc}
5. & $74-79$ & $73,5-79,5$ & 28 \\
6. & $80-85$ & $79,5-85,5$ & 17 \\
& $86-91$ & $85,5-91,5$ & 5 \\
\hline & Jumlah & & 92 \\
\hline
\end{tabular}

Berdasarkan tabel distribusi frekuensi tabel 3 bisa diketahui bahwa variabel motivasi kerja siswa memiliki frekuensi tertinggi yaitu sebesar 74-79 dan memiliki frekuensi relatif sebesar $30 \%$ dari total sampel, sedangkan frekuensi terendah yang terletak pada interval kelas 1 (satu) antara 50-55.

\section{Uji Normalitas}

Berikut adalah perhitungan uji normalitas variabel hasil belajar gambar teknik, motivasi kerja siswa dan hasil belajar instalasi penerangan listrik yang dapat dilihat pada Tabel 4.

Tabel 4. Uji normalitas Hasil Belajar Gambar Teknik, Motivasi Kerja Siswa dan Hasil Belajar Instalasi Penerangan Listrik

\begin{tabular}{|c|c|c|c|c|}
\hline Uji & DK & $x^{2}$ & $x^{2}$ & Ket \\
\hline Normalitas & & tabel & hitung & \\
\hline \multicolumn{5}{|l|}{ Hasil Belajar } \\
\hline Gambar & 6 & 12,59 & 8,11 & Normal \\
\hline Teknik & & & 6 & \\
\hline Motivasi & & & & \\
\hline Kerja & 6 & 12,59 & $\begin{array}{l}9,26 \\
0\end{array}$ & Normal \\
\hline $\begin{array}{l}\text { Hasil Belajar } \\
\text { Instalasi }\end{array}$ & & & & \\
\hline $\begin{array}{l}\text { Penerangan } \\
\text { Listrik }\end{array}$ & 6 & 12,59 & $\begin{array}{l}9,69 \\
7\end{array}$ & Normal \\
\hline
\end{tabular}

Pada tabel 4, variabel hasil belajar gambar teknik didapat $\chi_{\text {hitung }}^{2}=8,116$ sedangkan $\chi_{\text {tabel }}^{2}=12,59$, untuk $\alpha=0,05$ dan $\mathrm{dk}=6$. Karena $\chi^{2}$ hitung $\leq \chi^{2}$ tabel maka dapat disimpulkan bahwa penyebaran data variabel hasil belajar gambar teknik berdistribusi normal. Pada tabel 4 , variabel motivasi kerja didapat $\chi^{2}$ hitung $=9,260$ sedangkan $\chi_{\text {tabel }}^{2}=12,59$, untuk $\alpha=0,05$ dan $\mathrm{dk}=6$.Karena $\chi^{2}$ hitung $\leq \chi^{2}$ tabel maka dapat disimpulkan bahwa penyebaran data variabel motivasi kerja siswa berdistribusi normal. Pada tabel 4, variabel hasil belajar instalasi penerangan listrik didapat $\chi^{2}$ hitung $=9,697$ 
sedangkan $\chi_{\text {tabel }}^{2}=12,59$, untuk $\alpha=0,05$ dan $\mathrm{dk}=6$. Karena $\chi^{2}$ hitung $\leq \chi^{2}$ tabel maka dapat disimpulkan bahwa penyebaran data variabel hasil belajar instalasi penerangan listrik berdistribusi normal.

\section{Uji Linieritas}

Berikut adalah perhitungan uji linieritas hasil belajar gambar teknik dengan hasil belajar instalasi penerangan listrik yang dapat dilihat pada Tabel 5.

Tabel 5. Uji Linieritas Hasil Belajar Gambar Teknik dengan Hasil Belajar Instalasi Penerangan Listrik

\begin{tabular}{lllll}
\hline $\begin{array}{l}\text { Uji } \\
\text { Linieritas }\end{array}$ & $\mathbf{N}$ & $\begin{array}{l}\mathbf{F} \\
\text { hitung }\end{array}$ & $\begin{array}{l}\mathbf{F} \\
\text { tabel }\end{array}$ & Ket \\
\hline Hasil & & & & \\
$\begin{array}{l}\text { Belajar } \\
\text { Gambar }\end{array}$ & & & & \\
teknik & & & & \\
Dengan & 92 & 1,20 & 1,82 & Linier \\
Hasil & & & & \\
Belajar & & & & \\
Instalasi & & & & \\
Penerangan & & & & \\
Listrik & & & & \\
\hline
\end{tabular}

Berdasarkan hasil analisis varians(Anava) pada tabel 5 diketahui nilai variabel hasil belajar gambar teknik dengan hasil belajar instalasi penerangan listrik yaitu $F_{\text {hitung }}=1,20$ dengan derajat kebebasan (dk) pembilang sebesar 14 dan dk penyebut sebesar 76 dan taraf signifikansi $\alpha=5 \%$, maka diperoleh $\mathrm{F}_{\text {tabel }}$ $=1,82$. Dilihat dari kriteria pengujian yang digunakan, maka diperoleh hasil pengujian hipotesis tersebut menunjukkan $F_{\text {hitung }}<\mathrm{F}_{\text {tabel }}$ maka $\mathrm{H}_{0}$ diterima yang artinya terdapat persamaan linier antara hasil belajar gambar teknik dan hasil belajar instalasi penerangan listrik.

Selanjutnya adalah perhitungan uji linieritas motivasi kerja siswa dengan hasil belajar instalasi penerangan listrik yang dapat dilihat pada Tabel 6
Tabel 6. Uji Linieritas Motivasi Kerja Siswa Dengan Hasil Belajar Instalasi Penerangan

\begin{tabular}{lcccc}
\multicolumn{5}{c}{ Listrik } \\
\hline $\begin{array}{l}\text { Uji } \\
\text { Linieritas }\end{array}$ & $\mathbf{N}$ & $\begin{array}{l}\mathbf{F} \\
\text { hitung }\end{array}$ & $\begin{array}{l}\text { F } \\
\text { tabel }\end{array}$ & Ket \\
\hline Motivasi & & & & \\
Kerja siswa & & & & \\
$\begin{array}{l}\text { Dengan } \\
\text { Hasil }\end{array}$ & 92 & 0,85 & 1,67 & Linier \\
Belajar & & & & \\
Instalasi & & & & \\
Penerangan & & & & \\
Listrik & & & & \\
\hline
\end{tabular}

Berdasarkan hasil analisis varians(Anava) pada tabel 5 diketahui nilai variabel motivasi kerja siswa dengan hasil belajar instalasi penerangan listrik yaitu $F_{\text {hitung }}=0,85$ dengan derajat kebebasan (dk) pembilang sebesar 34 dan $\mathrm{dk}$ penyebut sebesar 56 dan taraf signifikansi $\alpha=5 \%$, maka diperoleh $\mathrm{F}_{\text {tabel }}=1,67$. Dilihat dari kriteria pengujian yang digunakan, maka diperoleh hasil pengujian hipotesis tersebut menunjukkan $\mathrm{F}_{\text {hitung }}<\mathrm{F}_{\text {tabel }}$ maka $\mathrm{H}_{0}$ diterima yang artinya terdapat persamaan linier antara motivasi kerja siswa dan hasil belajar instalasi penerangan listrik.

\section{Uji Hipotesis}

\section{Hubungan antara Hasil Belajar Gambar Teknik dengan Hasil Belajar Instalasi Penerangan Listrik}

Berikut adalah perhitungan uji hipotesis korelasi pearson product moment hasil belajar gambar teknik dengan hasil belajar instalasi penerangan listrik yang dapat dilihat Tabel 7.

Tabel 7. Uji korelasi Pearson Product Moment

\begin{tabular}{lllll}
\hline $\mathbf{N}$ & $\mathbf{A}$ & $\begin{array}{l}\mathbf{r} \\
\text { hitung }\end{array}$ & $\begin{array}{l}\mathbf{R} \\
\text { tabel }\end{array}$ & Ket \\
\hline 92 & 0,05 & 0,400 & 0,205 & $\begin{array}{l}\text { Ha } \\
\text { Diterima }\end{array}$ \\
\hline
\end{tabular}

\section{Hubungan Motivasi Kerja Siswa Dengan Hasil Belajar Instalasi Penerangan Listrik}

Berikut adalah perhitungan uji hipotesis korelasi pearson product moment motivasi kerja siswa dengan hasil belajar instalasi penerangan listrik yang dapat dilihat Tabel 8. 
Tabel 8. Uji korelasi Pearson Product Moment

\begin{tabular}{lllll}
\hline $\mathbf{N}$ & $\mathbf{A}$ & $\begin{array}{l}\mathbf{r} \\
\text { hitung }\end{array}$ & $\begin{array}{l}\mathbf{R} \\
\text { tabel }\end{array}$ & Ket \\
\hline 92 & 0,05 & 0,334 & 0,205 & $\begin{array}{l}\text { Ha } \\
\text { Diterima }\end{array}$ \\
\hline
\end{tabular}

\section{Hubungan Hasil Belajar Gambar Teknik dan Motivasi Kerja Siswa Dengan Hasil Belajar Instalasi Penerangan Listrik}

Berikut adalah perhitungan uji hipotesis korelasi pearson product moment hasil belajar gambar teknik dan motivasi kerja siswa dengan hasil belajar instalasi penerangan listrik yang dapat dilihat Tabel 9.

Tabel 9. Uji korelasi Pearson Product Moment

\begin{tabular}{lllll}
\hline $\mathbf{N}$ & $\mathbf{A}$ & $\begin{array}{l}\mathbf{r} \\
\text { hitung }\end{array}$ & $\begin{array}{l}\mathbf{r} \\
\text { tabel }\end{array}$ & Ket \\
\hline 92 & 0,05 & 0,513 & 0,205 & $\begin{array}{l}\text { Ha } \\
\text { Diterima }\end{array}$ \\
\hline
\end{tabular}

\section{KESIMPULAN DAN SARAN}

Berdasarkan hasil penelitian dan pembahasan data yang sudah dilakukan oleh peneliti menyatakan bahwa terdapat hubungan yang positif antara hasil belajar gambar teknik dengan hasil belajar instalasi penerangan listrik. Hal ini dibuktikan dari hasil perhitungan nilai rhitung $=0,400$ yang melebihi nilai dari rtabel=0,205 yang artinya antar variabel tersebut memiliki hubungan yang positif dan terbukti bahwa siswa dengan hasil belajar gambar teknik yang tinggi mampu meningkatkan hasil belajar instalasi penerangan listrik.

Hasil penelitian dan pembahasan data lainnya yang sudah dilakukan oleh peneliti menyatakan bahwa terdapat hubungan yang positif antara motivasi kerja siswa dengan hasil belajar instalasi penerangan listrik. Hal ini dibuktikan dari hasil perhitungan nilai rhitung=0,334 yang melebihi nilai dari rtabel $=0,205$ yang artinya antar variabel tersebut memiliku hubungan yang positif dan terbukti bahwa siswa yang memiliki motivasi kerja yang tinggi akan meningkatkan hasil belajar instalasi penerangan listrik.

Selanjutnya untuk hasil penelitian dan pembahasan data dapat diperoleh yang sudah dilakukan oleh peneliti menyatakan bahwa terdapat hubungan yang positif antara hasil belajar gambar teknik dengan hasil belajar instalasi penerangan listrik. Hal ini dibuktikan dari hasil perhitungan nilai rhitung $=0,513$ yang melebihi nilai dari rtabel=0,205 yang artinya antar variabel tersebut memiliku hubungan yang positif dan terbukti bahwa siswa akan memiliki hasil belajar instalasi penerangan listrik apabila siswa mampu meningkatkan hasil belajar gambar teknik dan motivasi kerjanya.

\section{Saran}

Berdasarkan hasil penelitian ini, peneliti dapat memberikan saran yaitu bagi siswa agar dapat mengoptimalkan hasil belajar gambar teknik dan motivasi kerja karena nantinya akan membantu kegiatan belajar instalasi penerangan listrik sehingga dapat meraih nilai yang maksimal, bagi guru sebagai masukan dan diimplementasikan agar hasil belajar gambar teknik dengan instalasi penerangan listrik menjadi lebih baik, guru harus memberikan pemahaman bahwa kegunaan gambar teknik sebagai dasar ilmu listrik secara kompleks, dan pemberian motivasi juga dapat dilakukan dengan membuat seminar yang mendatangkan alumni yang telah bekerja di industri atau dengan pengoptimalan bimbingan karir di sekolah sehingga dengan membangkitkan semangat dan termotivasi untuk bekerja,dapat meningkatkan hasil belajar yang tinggi. Bagi peneliti selanjutnya sebagai bahan pengetahuan dan masukan agar melakukan penelitian sejenis diharapkan mampu menemukan variabel lain yang lebih variatif dan luas sehingga dapat menambah hasil-hasil penelitian.

\section{DAFTAR PUSTAKA}

[1] Achjar Chalil. (2008).Pembelajaran Berbasis Fitrah, Jakarta:Balai Pustaka.

[2] Ahmad, Fathimah.2014. Pengaruh Lingkungan Belajar, Pembelajaran Praktik dan Kebiasaan Berpikir terhadap Hasil Belajar Siswa Pada Kelompok Mata Pelajaran Produktif Kelas XII TITL di SMK 1 Sedayu Bantul. [Skripsi].Yogyakarta: Universitas Negeri Yogyakarta https://eprints.uny.ac.id/28056/1/Fathimah 
\%20Ahmad-12501247007.pdf . Diakses pada 13 Juli 2019

[3] Sudjana,Nana. 1990. Penilaian Hasil Proses Belajar Mengajar. Bandung: PT Remaja Rosdakarya

[4] Arif, Muhammad. 2013. Hubungan antara Hasil Belajar Menggambar Teknik dengan Hasil Belajar Penerapan Dasar Instalasi Listrik Kelas X Jurusan TITL SMKN 1 Padang .http://ejournal.unp.ac.id/students/index.php / pte/ article/view/1021.Diakses pada 13 Juli .2019

[5] Prastya Irawan.2009. Cooperative Learning. Yogyakarta: Pustaka Belajar

[6] Sugiyanto, Rismawati. 2016. Pengaruh Minat Kerja, Prestasi Belajar dan Lingkungan Keluarga terhadap Motivasi Siswa SMK Memasuki Dunia Kerja.https://journal.unnes.ac.id/sju/index.p hp/eeaj/article/view/13573/7437. Diakses pada 18 Februari 2020

[7] Sugiyono. 2011. Metode Penelitian Pendidikan Pendekatan Kuantitatif Kualitatif dan $R \& D$. Bandung: Alfabeta. 